\title{
Characteristics of leaching agents for heavy metal extraction and safe utilisation of pig farm biogas residues
}

\author{
Liu Xueyu, Ma Jieqiong, Zhu Hongguang* \\ Modern Agricultural Science \& Engineering, Institute of Biomass Energy Research Centre, Tongji University, Shanghai 200092, China
}

\begin{abstract}
The continuous development of biogas engineering in recent years has been accompanied by an increasing number of biogas-residue types in the environment. The existence of various heavy metal elements in biogas residues, particularly excessive amounts of zinc and copper in pig farm biogas residues, hinders their safe utilisation. Several studies have focused on an effective composition for biogas residues or on their effects on soil and plants. However, few investigations regarding the removal of harmful substances from biogas residues have been conducted. The characteristics of heavy metals leached from pig farm biogas residues using eight types of leaching agents were analysed in this study. It is expected that, based on this study, different uses for biogas residues can be developed under the premise of security. The results showed that the most suitable extractant of heavy metals from pig farm biogas residues was EDTA- 2Na. The leaching rates increased over time. The leaching rates of copper and zinc after $2 \mathrm{~h}$ were $21.91 \%$ and $48.66 \%$, respectively. After being leached for $2 \mathrm{~h}$ by EDTA-2Na, the concentration of zinc met the requirements for moderate alkaline soil, according to the Control Limits against Harmful Substances in Composts for Agricultural Use (DB44/T 361-2006) standard.
\end{abstract}

\section{Introduction}

The existence of heavy metals in anaerobic fermentation residues has been widely discussed, becoming a public fact domestically and abroad [1, 2]. During the evaluation of potential risks derived from heavy metals in biogas slurry irrigation, Liu [3] observed that when additives were used in the pig feed, the heavy metal contents were higher than in the cattle slurry. Elements, such as copper, zinc, chromium, cadmium, lead, arsenic, nickel, manganese, and selenium were investigated by Ma [4], who observed that there was a certain risk without any effective treatment.

Biogas residues contain a lot of useful elements such as nitrogen, phosphorus, potassium., but the simultaneous existence of potentially harmful substances hinders its rapid and large effective use [5]. Neng-min Zhu [6] suggested that high heavy metal content in biogas residues will inevitably have negative effects on the soil and might lead to a fertiliser with a lower nutrient level. Therefore, the agro-ecological effects of various heavy metals should be evaluated. Copper and zinc should be carefully considered since their total contents were beyond the permissible values. Most studies focus on the effective composition of biogas residues or the effects of fertilisation on soils and plants [7-11]. However, there are only few studies on the removal of the cited harmful substances.

Leaching is the process of extracting soluble active ingredients from raw materials using suitable solvents and methods [12]. It is often carried out in batch tanks or by dispersing crushed solids in a liquid [13]. Extraction of heavy metals from soils has long been reported. There is an extensive range of extraction agents. Commonly used agents include: weak base solution, weak acid solution (arsenic extraction), buffer solution, neutral salt solution, and chelating agent. Their effects vary according to the soil characteristics. For example, different soil $\mathrm{pH}$ can lead to different extraction results.

$\mathrm{Li}$ and $\mathrm{Xu}$ [14] used hydrochloric acid, ethylene diamine tetraacetic acid (EDTA), and diethylene triamine pentaacetic acid (DTPA) as extractant agents. The results showed that the release rate of available copper significantly increased after adding the leaching agents, and the activation effect was achieved after adding the leaching agent for more than $2 \mathrm{~h}$. The amount of available cadmium and zinc in the soil samples increased with the addition of the leaching agent, even when the activation was not evident. In a short period, the release of lead in the soil samples was significantly higher than that in the control sample, which indicated that the extract had a clear and rapid activation effect on lead.

To some extent, biogas residues are similar to sediments. The bioavailability of heavy metals in sediments is reduced after desorption [15]. There are not as many studies on the extraction of biogas residues, but it is worth to analyse them as well. In this paper, we selected eight extractants, including distilled water, to be applied to the residue. The extractants were selected based on experience of other researchers and the characteristics of biogas residue. The next look for a

\footnotetext{
* Zhu Hongguang: zhuhg@,tongji.edu.cn
} 
variety of biogas residue utilisation of the way out, being aimed at seeking different roads to use the biogas residues under the premise of security.

\section{Subjects and methods}

\subsection{Test materials and reagents}

The biogas residue used in this experiment was collected from the Fumin Farm, in Chongming County, Shanghai. Pig manure was used as the raw material for fermentation. Some of the contents from the fresh biogas residue are as follows (Table 1).

Seven extractants were selected, and deionised water was used for the experiments. All the reagents were purchased from Sinopharm Group Chemical Reagent Co., Ltd. The configurations of the leaching agents are shown in Table 2.

Configuration method weigh the reagent; add the right amount of deionised water; after fully dissolved, transfer to a $1000 \mathrm{ml}$ volumetric flask; shake the sample; store in reagent bottles; stand-by.

Table 1. Content of heavy metals in biogas residues from experiments $(\mathrm{mg} / \mathrm{kg})$

\begin{tabular}{cccccccccc}
\hline Element & $\mathrm{As}$ & $\mathrm{Cd}$ & $\mathrm{Cr}$ & $\mathrm{Cu}$ & $\mathrm{Mn}$ & $\mathrm{Ni}$ & $\mathrm{TP}$ & $\mathrm{Pb}$ & $\mathrm{Zn}$ \\
Total amount (dry weight) & 7.38 & Undetected & 8.57 & 776.87 & 557.13 & 5.10 & 28452.42 & 2.05 & 3493.84 \\
\hline
\end{tabular}

Table 2. Selection and preparation of extractants

\begin{tabular}{cccc}
\hline Name & Target level (mol/L) & Amount of reagent (reagent name)(g) & Constant volume(ml) \\
\hline Citric acid & 0.1 & 21.014 (monohydrate citric acid) & 1000 \\
Oxalic acid & 0.1 & 12.607 (sodium oxalate dihydrate) & 1000 \\
Tartaric acid & 0.1 & 15.009 (1--tartaric acid) & 1000 \\
EDTA-2Na & 0.05 & 18.612 (ethylene diamine tetraacetic acid) & 1000 \\
Ammonium chloride & 0.1 & 5.349 (ammonium chloride) & 1000 \\
Sodium thiosulfate & 0.1 & 24.818 (sodium thiosulfate pentahydrate) & 1000 \\
Trisodium citrate dihydrate & 0.1 & 29.410 (trisodium citrate dihydrate) & 1000 \\
\hline
\end{tabular}

\subsection{Extraction method}

Twenty grams of fresh biogas residue (including water) were placed in a $250 \mathrm{ml}$ plastic bottle. Then, $100 \mathrm{ml}$ of the extractant was added to the sample, which was shaken at $180 \mathrm{r} / \mathrm{min}$ on a constant shaker, at $20{ }^{\circ} \mathrm{C}$. At intervals of $15 \mathrm{~min}, 30 \mathrm{~min}, 45 \mathrm{~min}$, and $60 \mathrm{~min}, 12-13$ $\mathrm{ml}$ were sampled, then centrifuged at $5000 \mathrm{r} / \mathrm{min}$ for 3 min. After that, the sample was filtered through a 0.45 $\mu \mathrm{m}$ water-based membrane filter.

\subsection{Determination method}

Arsenic, cadmium, chromium, copper, nickel, lead, and zinc were determined by ICP-AES. The Agilent 720ES instrument was used with the following parameters: 15.0 $\mathrm{L} / \mathrm{min}$ plasma flow; $0.75 \mathrm{~L} / \mathrm{min}$ nebuliser flow; 1.5 $\mathrm{L} /$ min cooling gas flow; $1.2 \mathrm{KW}$ radio frequency power; $15 \mathrm{r} / \mathrm{min}$ pump speed; $10 \mathrm{~s}$ flush time; $20 \mathrm{~s}$ delay time; $15 \mathrm{~s}$ read time; $45 \mathrm{~s}$ wash time; three replicates (each sample was read four times). Analyses were performed at $188.98 \mathrm{~nm}, 214.43 \mathrm{~nm}, 267.72 \mathrm{~nm}, 327.35 \mathrm{~nm}, 231.60$ $\mathrm{nm}, 220.35 \mathrm{~nm}$, and $213.88 \mathrm{~nm}$, for arsenic, cadmium, chromium, copper, nickel, lead, and zinc, respectively.

\subsection{Data analysis method}

The heavy metal concentrations in the biogas residues were compared with the standards for environmental quality of soil, organic fertilisers, and anaerobic digested fertilisers. The goal is to not exceed the soil environmental quality standards.

For that, the contents of heavy metals before and after leaching were analysed. The feasibility of safe utilisation of the biogas residue will be discussed. IBM SPSS Statistics 22.0 was applied to analyse the results. The limits of heavy metal concentration from three standards are shown in Table 3.

\section{Results and analysis}

\subsection{Comparative analysis before treatment}

From Table 4, it can be observed that the maximum values of arsenic, cadmium, chromium, and lead were not exceeded before treatment. In contrast, the contents of copper and zinc exceeded the maximum limit for the environmental quality standard for soils. Therefore, a long-term, unplanned, or unlimited fixed-point return can lead to a risk of excessive copper and zinc in the soil. 
Table 3. Limits of heavy metal according to three standards $(\mathrm{mg} / \mathrm{kg})$

\begin{tabular}{|c|c|c|c|c|c|c|c|c|c|c|c|c|}
\hline \multicolumn{3}{|c|}{$\begin{array}{l}\text { Elements } \\
\text { Reference Standard }\end{array}$} & \multicolumn{2}{|c|}{ As $\leq$} & \multirow{2}{*}{$\begin{array}{l}\mathrm{Cd} \\
\leq\end{array}$} & \multicolumn{2}{|c|}{$\mathrm{Cr} \leq$} & \multicolumn{2}{|c|}{$\mathrm{Cu} \leq$} & \multirow{2}{*}{$\begin{array}{l}\mathrm{Ni} \\
\leq\end{array}$} & \multirow{2}{*}{$\begin{array}{l}\mathrm{Pb} \\
\leq\end{array}$} & \multirow{2}{*}{$\begin{array}{c}\mathrm{Zn} \\
\leq\end{array}$} \\
\hline \multirow{6}{*}{$\begin{array}{c}\text { Environmental } \\
\text { quality } \\
\text { standard for } \\
\text { soils }[16]\end{array}$} & Level & Soil pH & $\begin{array}{l}\text { Paddy } \\
\text { field }\end{array}$ & Dryland & & $\begin{array}{c}\text { Paddy } \\
\text { field }\end{array}$ & Dryland & $\begin{array}{l}\text { Farmlan } \\
\text { d etc. }\end{array}$ & $\begin{array}{c}\text { Orchar } \\
\mathrm{d}\end{array}$ & & & \\
\hline & I & $\begin{array}{c}\text { Natural } \\
\text { background }\end{array}$ & 15 & 15 & 0.20 & 90 & 90 & 35 & - & 40 & 35 & 100 \\
\hline & & $<6.5$ & 30 & 40 & 0.30 & 250 & 150 & 50 & 150 & 40 & 250 & 200 \\
\hline & II & $6.5 \sim 7.5$ & 25 & 30 & 0.30 & 300 & 200 & 100 & 200 & 50 & 300 & 250 \\
\hline & & $>7.5$ & 20 & 25 & 0.60 & 350 & 250 & 100 & 200 & 60 & 350 & 300 \\
\hline & III & $>6.5$ & 30 & 40 & 1.0 & 400 & 300 & 400 & 400 & 200 & 500 & 500 \\
\hline \multicolumn{3}{|c|}{ Organic fertiliser[17] } & \multicolumn{2}{|c|}{15} & 3 & \multicolumn{2}{|c|}{150} & \multicolumn{2}{|c|}{-} & - & 50 & - \\
\hline \multicolumn{3}{|c|}{ Anaerobic digested fertiliser[18] } & \multicolumn{2}{|c|}{15} & 3 & \multicolumn{2}{|c|}{150} & \multicolumn{2}{|c|}{-} & - & 50 & - \\
\hline
\end{tabular}

Note: I :Soil limits for the protection of regional natural ecology, to maintain the natural background; II : Soil limits for the protection of agricultural production, to maintain human health; III: Soil limits to ensure agricultural and forestry production and normal plant growth.

Table 4. Limits of heavy metal according to three standards ( $\mathrm{mg} / \mathrm{kg}$ )

\begin{tabular}{cccc}
\hline Name & Target level $(\mathrm{mol} / \mathrm{L})$ & Amount of reagent (reagent name) $(\mathrm{g})$ & Constant volume $(\mathrm{ml})$ \\
\hline Citric acid & 0.1 & 21.014 (monohydrate citric acid) & 1000 \\
Oxalic acid & 0.1 & 12.607 (sodium oxalate dihydrate) & 1000 \\
Tartaric acid & 0.1 & 15.009 (l--tartaric acid) & 1000 \\
EDTA-2Na & 0.05 & 18.612 (ethylene diamine tetraacetic acid) & 1000 \\
Ammonium chloride & 0.1 & 5.349 (ammonium chloride) & 1000 \\
Sodium thiosulfate & 0.1 & 24.818 (sodium thiosulfate pentahydrate) & 1000 \\
Trisodium citrate dihydrate & 0.1 & 29.410 (trisodium citrate dihydrate) & 1000 \\
\hline
\end{tabular}

\subsection{Results and statistical analysis of extraction}

\subsubsection{Concentration of extracted elements}

Concentrations of nickel, cadmium, and lead were not detected. The extraction results of arsenic, chromium, zinc, and copper are shown in Fig.1.

Fig. 1. Histogram of extract concentration
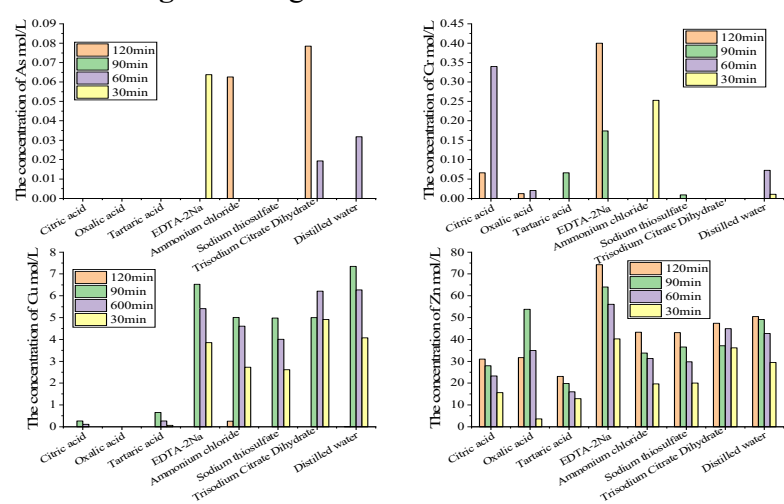

Arsenic concentrations after leaching by citric acid, oxalic acid, tartaric acid, and sodium thiosulfate were below the detection limit. Arsenic leaching by trisodium citrate increased with time. Arsenic leaching by EDTA-
$2 \mathrm{Na}$ occurred at $30 \mathrm{~min}$, by ammonium chloride at 120 $\mathrm{min}$, and by distilled water at $60 \mathrm{~min}$.

Cadmium leaching by EDTA-2Na increased with longer times. Cadmium leaching by citric acid occurred at $60 \mathrm{~min}$, and by ammonium chloride at $30 \mathrm{~min}$.

From the zinc extraction results, EDTA-2Na presents considerable advantages compared with other extracts. Apart from oxalic acid, extraction increased with longer extraction time. Because oxalic acid is easily decomposed, it led to leaching instability.

From the copper extraction results, EDTA-2Na also showed good results compared with other extractants. To extract copper from biogas residue, salts are more effective than acids.

\subsubsection{Statistical analysis of extract concentration}

Table 5 demonstrates the statistical analysis of the effects of different extractants on heavy metals at different times. It shows the extractant leaching range (maximum and minimum) and the discretisation of extract concentration (standard deviation).

Since the contents of nickel and lead were very low, and cadmium was not detected, nickel, lead, and cadmium were considered "undetected" after the leaching process. 
Table 5. Analysis of the results of heavy metal extraction by eight extractants

\begin{tabular}{|c|c|c|c|c|c|c|c|}
\hline $\begin{array}{l}\text { Elemens } \\
\text { Parameter }\end{array}$ & As & $\mathrm{Cr}$ & $\mathrm{Zn}$ & $\mathrm{Cu}$ & $\mathrm{Ni}$ & $\mathrm{Cd}$ & $\mathrm{Pb}$ \\
\hline Average & 0.0080 & 0.0647 & 35.095 & 3.427 & Undetected & Undetected & Undetected \\
\hline SD & 0.0209 & 0.1793 & 15.499 & 2.782 & - & - & - \\
\hline Variance & 0.0004 & 0.0321 & 240.204 & 7.741 & - & - & - \\
\hline Min & Undetected & Undetected & 3.607 & Undetected & Undetected & Undetected & Undetected \\
\hline Max & 0.0785 & 0.8665 & 74.267 & 7.674 & Undetected & Undetected & Undetected \\
\hline
\end{tabular}

The results showed that all eight leaching agents had different degrees of zinc leaching. The maximum leaching concentration was $74.27 \mathrm{mg} / \mathrm{L}$ by EDTA-2Na at $120 \mathrm{~min}$, and the minimum was $3.61 \mathrm{mg} / \mathrm{L}$ by oxalic acid at $30 \mathrm{~min}$. The maximum leaching concentration of copper was $7.67 \mathrm{mg} / \mathrm{L}$ by distilled water at $120 \mathrm{~min}$, of arsenic it was $0.079 \mathrm{mg} / \mathrm{L}$ by trisodium citrate at 120 min. The discretisation of the extracts concentrations by all leaching agents was zinc $>$ copper $>$ chromium $>$ arsenic $=$ nickel $=$ cadmium $=$ lead.

\subsection{Results and statistical analysis of extraction rate}

\subsubsection{Results of extraction rate}

The arsenic extraction rate by EDTA-2Na was $19.63 \%$ at 30 min. EDTA-2Na also showed a good balance between chromium (106.11\%), zinc (48.24\%), and copper $(21.91 \%)$ leaching at $120 \mathrm{~min}$. The extraction rate increased with extraction time. The leaching of arsenic by trisodium citrate also showed an increase trend with time. The extraction rate was $24.16 \%$ at $120 \mathrm{~min}$, but there was not a good removal efficiency for other metals. Distilled water was slightly more effective for copper extraction than EDTA-2Na, but there was no competitive advantages for the removal of other metal elements.

As shown in Fig. 2, the leaching of zinc increased with time for all leaching agents except oxalic acid. It reached a maximum extraction of $48.24 \%$. Oxalic acid fluctuations were relatively large. The removal rates by distilled water, trisodium citrate, sodium thiosulfate, and ammonium chloride at 120 min were $33.20 \%, 31.23 \%$, $28.41 \%$, and $28.55 \%$, respectively. Before $60 \mathrm{~min}$, the effect of trisodium citrate is slightly superior than of sodium thiosulfate and ammonium chloride. The leaching rate of zinc by EDTA-2Na increased steadily with time, with a maximum of $48.66 \%$ at $120 \mathrm{~min}$.

\subsubsection{Statistical analysis of extraction rate}

In general, the extraction rates vary significantly. The maximum amount of arsenic leaching was $24.16 \%$. EDTA-2Na at $120 \mathrm{~min}$ achieved total chromium leaching. The maximum extraction of zinc and copper was $48.24 \%$ and $22.45 \%$, respectively. The discretisation of the leaching rates is chromium $>$ zinc $>$ copper $>$ arsenic $=$ nickel $=$ cadmium $=$ lead.
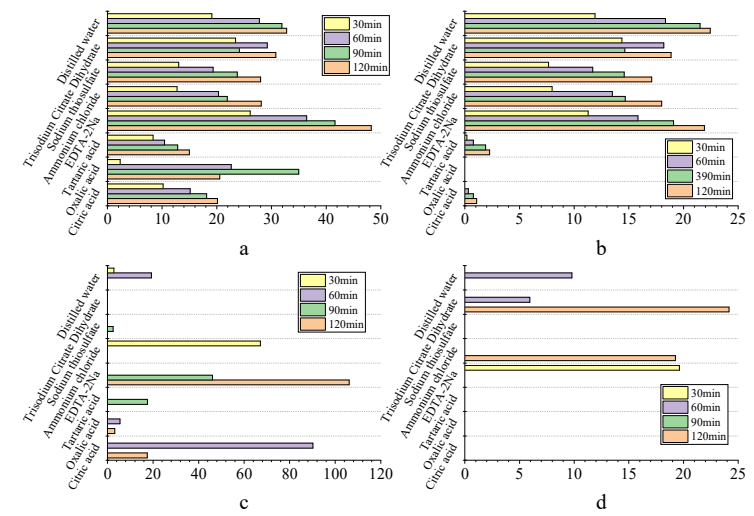

Fig. 2. Bar chart of extraction rate ( $a$ 。 Extraction to rate of $\mathrm{Zn} \% \mathrm{~b}$ 。 Extraction to rate of $\mathrm{Cu} \% \mathrm{c}$ 。 Extraction to rate of $\mathrm{Cr} \% \mathrm{~d}$ 。 Extraction to rate of As \%)

\subsection{Comparative analysis of concentrations of heavy metals in biogas residue after EDTA-2Na treatment}

In this section, the concentrations of heavy metals in the biogas residue after EDTA-2Na extraction for $2 \mathrm{~h}$ are analysed and compared with the appropriate standards. The dry weight of heavy metals in the biogas residue after EDTA-2Na treatment is shown in Table 6.

\subsubsection{Analysis and comparison with soil environmental quality standards}

As observed, arsenic, cadmium, chromium, copper, and lead did not exceed the environmental quality standards for soils of classI, organic fertilisers, and biogas. Figure 3 shows the excess of copper and zinc compared to multiple soil environmental quality standards before and after treatment.

After treatment with EDTA-2Na, the concentration of zinc in the biogas residue that exceeded the environmental quality standard for soil of class I decreased from 34.94 times to 18.08 times. For soil of class III, it reduced from 6.99 times to 3.62 times. The excess of copper also declined.

If we consider that the biogas residue disposal is done through return to the farmland, and that they do not affect soil safety, the leaching treatment can increase the amount of biogas residue. The corresponding dilution factor can be reduced, and the maximum loading capacity of biogas residue can be increased. 
Table 6. Analysis of extraction by eight extractants

\begin{tabular}{cccccccc}
\hline Elements & $\mathrm{As}$ & $\mathrm{Cr}$ & $\mathrm{Zn}$ & $\mathrm{Cu}$ & $\mathrm{Ni}$ & $\mathrm{Cd}$ & $\mathrm{Pb}$ \\
\hline Average & 2.46 & 11.80 & 22.80 & 10.03 & 0 & 0 & 0 \\
SD & 6.42 & 27.00 & 10.07 & 8.14 & - & - & - \\
Variance & 41.21 & 729.15 & 101.35 & 66.25 & - & 0 & 0 \\
Min & 0 & 0 & 2.34 & 0 & 0 & 0 & 0 \\
Max & 24.16 & 106.11 & 48.24 & 22.45 & 0 & 0 \\
\hline
\end{tabular}

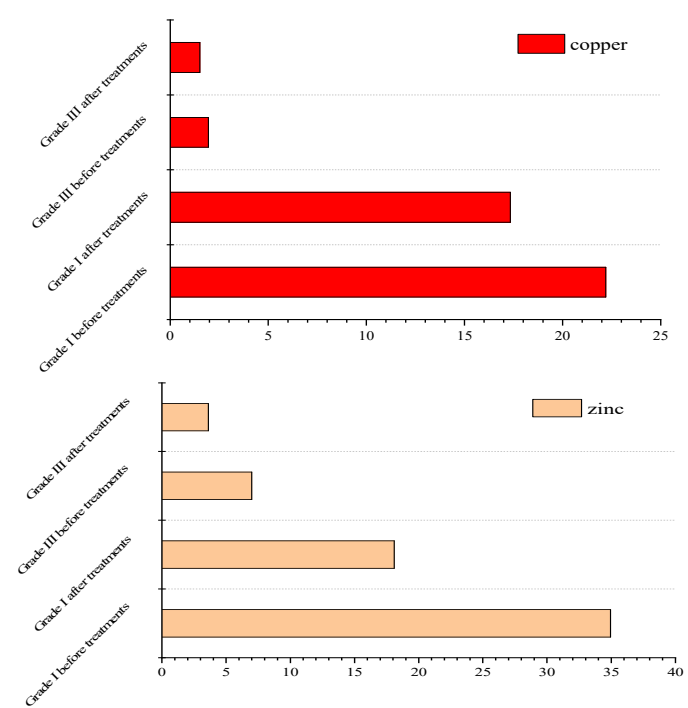

Fig. 3. Bar chart of exceeding copper and zinc in biogas residue before and after EDTA-2Na treatment

\subsubsection{Analysis and comparison with the Guideline for Safety Application of Zinc Fertiliser and the Control Limits against Harmful Substances in Composts for Agricultural Use}

The EDTA-2Na-treated biogas residues meet the requirements of allowable contents in agricultural chemical compost for neutral and alkaline soils (Table 7). Therefore, it is theoretically proved that the biogas residue compost is feasible for neutral and alkaline soils.

Table 7. Amount of heavy metals in the biogas residue after EDTA-2Na treatment (dry weight) $(\mathrm{mg} / \mathrm{kg})$

\begin{tabular}{ccccc}
\hline Elements & $\mathrm{As}$ & $\mathrm{Cd}$ & \multicolumn{2}{c}{$\mathrm{Cr}$} \\
Weight & 7.38 & Not detected & \multicolumn{2}{c}{ Not detected } \\
\hline Elements & $\mathrm{Cu}$ & $\mathrm{Ni}$ & $\mathrm{Pb}$ & $\mathrm{Zn}$ \\
Weight & 606.66 & 5.10 & 2.05 & 1808.39 \\
\hline
\end{tabular}

Table 8 shows the limits for heavy metal content in manure from livestock and poultry. The zinc content of the residue after EDTA-2Na treatment meets the requirements for dryland crops and fruit trees in alkaline soils. Copper also satisfies the requirements for fruit trees in alkaline soils. Concerning the standard for general classification of fertiliser quality [20], if the heavy metal content is $10 \%$ or more, the fertiliser is considered inferior. The copper content was 606.66 $\mathrm{mg} / \mathrm{kg}$, which is acceptable for neutral-alkaline fields.
Therefore, the use of fertilisers based on biogas residues from pig farms for fruit trees in alkaline soil is feasible, and the use for dry crops in neutral and alkaline soils can be considered.

Table 8. Maximum allowable levels of chemical contaminants for agricultural composting $[19](\mathrm{g} / \mathrm{kg})$

\begin{tabular}{ccc}
\hline Project & $\begin{array}{c}\text { For acid soil } \\
(\mathrm{pH}<6.5)\end{array}$ & $\begin{array}{c}\text { For neutral and } \\
\text { alkaline soils }(\mathrm{pH} \geq 6.5)\end{array}$ \\
\hline Total arsenic $\leq$ & 75 & 75 \\
Total cadmium $\leq$ & 5 & 20 \\
Total chromium $\leq$ & 600 & 1000 \\
Total copper $\leq$ & 500 & 1000 \\
Total nickel $\leq$ & 100 & 200 \\
Total lead $\leq$ & 200 & 500 \\
Total zinc $\leq$ & 1000 & 2000 \\
\hline
\end{tabular}

Zinc fertilisers should be applied to medium and below soils, particularly for soils with high $\mathrm{pH}$ and low sand or organic matter content. The amount of zinc applied to crop soils is determined by the soil capacity to supply zinc. Table 9 shows the recommended zinc dosage according to the standards.

Table 9. Limits of heavy metal content in manure made from livestock and poultry [21] (dry fecal content) $(\mathrm{mg} / \mathrm{kg})$

\begin{tabular}{ccccc}
\hline \multirow{2}{*}{ Project } & \multicolumn{3}{c}{ Soil pH } \\
\hline \multirow{4}{*}{ Arsenic } & $<6.5$ & $6.5 \sim 7.5$ & $>7.5$ \\
& Field crop & 50 & 50 & 50 \\
& Rice & 50 & 50 & 50 \\
& Fruit trees & 50 & 50 & 50 \\
& Vegetables & 30 & 30 & 30 \\
\cline { 2 - 5 } Copper & Field crop & 300 & 600 & 600 \\
& Rice & 150 & 300 & 300 \\
& Fruit trees & 400 & 800 & 800 \\
& Vegetables & 85 & 170 & 170 \\
\cline { 2 - 5 } Zinc & Field crop & 2000 & 2700 & 3400 \\
& Rice & 900 & 1700 & 1500 \\
& Fruit trees & 1200 & 1200 & 2000 \\
& Vegetables & 500 & 700 & 900 \\
\hline
\end{tabular}

The amounts of zinc in the residue were 3493.84 $\mathrm{mg} / \mathrm{kg}$ (dry) and $769.75 \mathrm{mg} / \mathrm{kg}$ (moist). The target amounts of zinc and the different reference units are shown in Table 10. The biogas residue can be dried as a base fertiliser and applied to soils with poor or medium zinc contents for high-zinc content crops. 
The results by Guo [23] showed that the highest yield from organic manure, sheep manure, BGA, and biogas residue were $11.45,7.90,8.02$, and $10.88 \mathrm{t} / \mathrm{hm} 2$, respectively. Therefore, the amounts of biogas residue listed in Table 11 are reasonable.

Table 10. Recommended dosage of zinc [22] (convert zinc $\mathrm{kg} / \mathrm{hm} 2$ )

\begin{tabular}{cccc}
\hline $\begin{array}{c}\text { Zinc supply } \\
\text { capacity of soil }\end{array}$ & $\begin{array}{c}\text { Highly sensitive } \\
\text { crops to zinc }\end{array}$ & $\begin{array}{c}\text { Sensitive } \\
\text { to zinc }\end{array}$ & $\begin{array}{c}\text { Not } \\
\text { sensitive } \\
\text { to zinc }\end{array}$ \\
\hline Very low & 3.0 & $1.5 \sim 3.0$ & $0.75 \sim 1.5$ \\
Low & $1.5 \sim 3.0$ & $0.75 \sim 1.5$ & - \\
Medium & $0.75 \sim 1.5$ & - & - \\
High & - & - & - \\
\hline
\end{tabular}

Table 11. Conversion of different units of the measurement amount of dry residue and wet slag according to the different goals of zinc consumption

\begin{tabular}{cccc}
\hline Target amount of zinc & Reference unit & $\mathrm{t} / \mathrm{hm}^{2}$ & $\begin{array}{c}\mathrm{kg} / 667 \\
\mathrm{~m}^{2}(\mathrm{mu})\end{array}$ \\
\hline Dry biogas & 3.0 & 0.86 & 57.26 \\
residue & 1.5 & 0.43 & 28.63 \\
& 0.75 & 0.21 & 14.31 \\
Wet biogas & 3.0 & 3.90 & 259.82 \\
residue & 1.5 & 1.95 & 129.91 \\
& 0.75 & 0.97 & 64.96 \\
\hline
\end{tabular}

Note: The water content of biogas residue for this research was $78 \%$.

\section{Discussion}

\subsection{Rationality of EDTA-2Na as extractant of heavy metals}

Through the data analysis above, leaching of various metals by EDTA-2Na is more even and has significant advantages compared with other extraction agents. Similar conclusions have been demonstrated in previous researchers. Four extraction reagents, HAc-NaAc $(0.5$ $\mathrm{mol} / \mathrm{L})$ buffer solution, $\mathrm{CaCl} 2$, DTPA $(0.005 \mathrm{~mol} / \mathrm{L})$, and EDTA-2Na $(0.05 \mathrm{~mol} / \mathrm{L})$, have been used to leach copper, zinc, nickel, and cadmium from the soil by professors Yi and Zhang [24]. Their results also showed that EDTA-2Na was the most suitable extraction agent.

The effects of different extracts on acid, neutral, and alkaline soils, and the correlations between different heavy metals and soil types were analysed by Li [25]. The results showed that EDTA-2Na was the most suitable extractant, with superior extraction efficiency for copper, lead, and chromium in three typical soils. The leaching results of copper and chromium were consistent with the present study. The lead content was not compared because it was too low in the biogas residue.

As a disodium salt of EDTA, EDTA-2Na has been reported to have good metal extraction properties. The morphology of copper and zinc in six types of biogas residues by $\mathrm{CaCl} 2$, EDTA, one-step extraction method using HOAc, and an improved BCR three-step extraction method, have been studied. The results showed that the extraction efficiency of copper and zinc was EDTA > $\mathrm{HOAc}>\mathrm{CaCl} 2$, in which EDTA extraction efficiency can be up to $70 \%$, and the mobility of zinc is greater than of copper [26]. The extraction of copper and lead in soils by solutions of EDTA, CIT, SDS, and RL2 was studied by Liu [27]. The results showed that $0.01 \mathrm{~mol} / \mathrm{L}$ EDTA was the optimum concentration, and the leaching percentage of heavy metals was $63.73 \%$ for copper and $88.48 \%$ for lead, which shows that EDTA is more effective for lead than for copper removal. EDTA has been widely reported as a leaching agent, but the solubility of EDTA in water is small, and its operation is not easy. However, according to the experimental results of this study, EDTA-2Na is stable, easy to operate, and effective. These are important conclusions considering the usual shortcomings. Therefore, EDTA-2Na can be established as a leaching agent that can comprehensively remove most heavy metals.

\subsection{Factors affecting the extraction efficiency}

1) Leaching agent species: As it can be observed by the data provided in this paper, the extraction effects of different leaching agents on the same metal are significantly different. In addition, different leaching agents have different leaching mechanisms. Shao [15] studied desorption of heavy metals in river sediments by chelating agents. The results showed that the effect of various factors on the desorption rate was chelant type $>$ chelating agent concentration $>$ desorption time.

2) Extraction time: According to the results, increased extraction time improved most extraction effects of the leaching agents, except for oxalic acid, which had wide fluctuations over time. According to the study by $\mathrm{Xu}$ [28], the extraction rates of cadmium, lead, copper, and zinc in contaminated soils increased with time. The leaching rates in moderate-polluted soils were higher than those in low-polluted soils. After $720 \mathrm{~min}$ reaction, the desorption rates of cadmium, lead, copper, and zinc in the moderate- and low-polluted soils were $45.16 \%$ and $30.88 \%, 51.32 \%$ and $26.45 \%, 17.86 \%$ and $14.23 \%$, and $23.31 \%$ and $19.63 \%$, respectively. The leaching rate in moderate-contaminated soils was higher than in low-contaminated soils. The rates decreased with prolonged desorption time.

3) Concentration of extractant: Pingan and Nanhui[29] observed that with increased tartaric acid, acetic acid, citric acid, and malic acid, the extraction rates of cadmium, lead, and zinc from the soil increased. The effects of these four organic acids on soil heavy metals were cadmium $>$ lead $>$ zinc. The results also showed that $0.5 \mathrm{~mol} / \mathrm{L}$ of tartaric acid had the best extraction efficiency of soil cadmium, lead, and zinc, with extraction rates of $99.39 \%, 57.65 \%$, and $43.52 \%$, respectively.

4) Other ancillary measures: Extraction efficiency can be improved through a combination of extraction agents and other physical, chemical, or biological methods. Eun Jung Kim [30] showed that the combination of dithionite and EDTA can effectively and simultaneously extract arsenic and heavy metals from 
soils under a wide range of $\mathrm{pH}$ conditions. The most economical method for metal recovery from biosorption on bacterial surface is elution by addition of appropriate solvents such as $\mathrm{HNO} 3, \mathrm{HCl}$, or $\mathrm{H} 2 \mathrm{SO} 4$. The amount of leaching is not determined by the type of mineral acid, but by the concentration of $\mathrm{H}+[31]$.

\subsection{Safe utilisation of biogas residue}

The main components of biogas residues include unfermented raw materials, microorganisms that are involved in the anaerobic fermentation process, as well as new microorganisms produced during fermentation. Biogas residues are rich in nutrients, have a high value in use, and a variety of purposes.

1) Use as fertiliser

In addition to being used as a zinc fertiliser, biogas residues are commonly used to produce other fertilisers. $\mathrm{Yu}$ [32] studied compound fertilisers composed by a mix of biogas residues from Municipal Solid Waste, fly ash, urea, diammonium phosphate, and potassium chloride at various ratios. The results showed that the organicinorganic compound fertiliser had significant effect on flowering. Xie [33] observed that a mixing ratio of $60 \%$ biogas and $40 \%$ chemical fertiliser was conducive to plant growth and could reduce accumulation of heavy metals in the soil. Duan [34] observed that biogas fertilisers contain a certain amount of heavy metals. Among them, the contents of copper and zinc in the test soils were significantly higher than in the control sample after long-term application. However, they did not exceed the environmental quality standard for soils. The content of arsenic and chromium in the biogas fertiliser was not high. After long-term application, their content in the soil showed a slight decrease trend or no obvious change. The evaluation of soil quality showed that the quality of all sampling sites did not change after the application of the biogas fertiliser. In addition, all of them met grade I or II of the national soil environmental quality standard. Comparing the biogas residues from chicken, cow, and pig manure, the nutrient content in the cow manure biogas fertiliser was the highest and in the chicken manure biogas fertiliser was the lowest. However, after long-term application, the most significant one was the swine manure biogas fertiliser.

The results of this study showed that biogas residues can meet the requirements to avoid chemical pollution from agricultural compost for application on neutral and alkaline soils. The pig manure was safe for use after anaerobic fermentation and leaching.

2) Biogas residue use as artificial substrate

A cultivation test conducted by Wei [5] demonstrated that cow dung residues can replace peat completely. Pig manure and chicken manure can partially replace peat. Their effects on seedling raising is better than of peat, vermiculite, and perlite. Zhao [35] mixed corn stover fermentation residue with vermiculite, changing the breathable matrix. The ratio of biogas residue to vermiculite was 1:2 and 1:3. They promoted root development and accumulated more dry matter. Zhu[36] used biogas residue and slag as raw materials. It was observed that biogas residues can increase the substrate values of $\mathrm{pH}$ and $\mathrm{EC}$, leading to a higher number of microbes in the matrix, enhanced matrix enzyme activity, superior root growth, increased height, stem diameter, and leaf number of tomato plants, and so on.

3) Biogas residue for soil improvement

Luo [37] modified lime clay with organic fertiliser. The study showed that a combination of pond mud, residue (liquid), and fresh green manure can reduce $\mathrm{pH}$, decrease calcium and magnesium contents, and enhance soil erosion capacity.

Wang [38] observed that after the application of residue from anaerobic fermentation, vegetable growth status and chromium residues were better than the control treatment. Cabbage yield increased by $66.2 \%$ on average. Residual chromium decreased by $42.9 \%$. After the anaerobic fermentation residue entered the chromium-contaminated soil, the chromium morphological distribution changed. The ratio of watersoluble and exchangeable chromium in the soil decreased. The proportion of sediments and residual state increased, and the effects of chromium in the soil decreased. Nitrogen mineralisation and adsorption of phosphorus and potassium were affected by the anaerobic fermentation residue. The soil capacity to supply nitrogen, phosphorus, and potassium was improved at different degrees.

Swine residue can contain hazardous substances which are harmful to the environment, hindering its use. However, after reasonable treatment, an acceptable safety degree can be achieved.

check with the conference organiser whether or not this is the case. If the print version will be black and white only, you should check your figure captions carefully and remove any reference to colour in the illustration and text. In addition, some colour figures will degrade or suffer loss of information when converted to black and white, and this should be taken into account when preparing them.

\section{Conclusion}

1) EDTA-2Na can evenly extract heavy metals from biogas residues with a significant removal efficiency.

2) After $2 \mathrm{~h}$ of EDTA-2Na extraction, the biogas residue from pig farming achieved the maximum allowable contents required by the Control Limits against Harmful Substances in Composts for Agricultural Use (DB44/T 361-2006) for neutral and alkaline soils. The use of biogas residues from pig farms as fertilisers for fruit trees in alkaline soils is feasible. The use for dry crops in neutral and alkaline soils can also be considered. After EDTA-2Na extraction and composting treatment, the use in alkaline soils is feasible.

3) The content of copper and zinc in the biogas residue exceeded the environmental quality standard for soil, so there is a risk of direct field return. The biogas residue after EDTA-2Na treatment can be directly applied to the soil after dilution with 3.6 times soil (or other equivalent method), though strict control and monitoring of the zinc content in the soil are necessary. 
4) According to the Guideline for Safety Application of Zinc Fertiliser, the biogas residue can be dried and used as a base fertiliser to be applied in soils with low or medium zinc content for crops with high zinc demands.

This work was supported by the "National Key R\&D Program of China" (Grant No. 2018YFD0800103 \& Grant No. 2018YFC1903204). The authors would also like to express their gratitude to Ma Jieqiong, Shen Wenyan, Fan Min, Fan Biying, Wang Yaohua, Chen Tinghua, and all personnel working in the field for their support and suggestions.

\section{References}

[1] B. Demirel, Göl. N. P, Onay T T. J MATER CYCLES WASTE, 15,3:409 (2015)

[2] H. M. Jin, Z.Z. Chang. APPL BIOCHEM BIOTECH, 164,3:268-282 (2011)

[3] S. C. Liu, L.W. Wang, X.X. Li, Y.C. Chen, M. M.Fu. Plant Nutrition and Fertilizer Science, 6:1517-1524. (2014) (in Chinese with English abstract)

[4] J. Q. Ma, H. G. Zhu, M. Fan. International Journal of Agricultural \&amp; Biolog..., 6,4:35-43(2013)

[5] Q.Y.Wei. Beijing University of Chemical Technology, (2014) (in Chinese with English abstract)

[6] N.M. Zhu, T. Luo, X.J. Guo, H. Zhang, Y. Deng. Environ Technol, 36,(5-8):992-1000 (2015)

[7] M. Fan, H.G. Zhu, J Q.Ma. International Journal of Agricultural, 7.1:1-10(2014)

[8] H. Insam, M. Gómez-Brandón, J. Ascher. SOIL BIOL BIOCHEM ,84:1-14. (2015)

[9] H. Coban, A. Miltner, M. Kästner. SOIL BIOL BIOCHEM, 2,91:58-64(2015).

[10] H. Coban, A. Miltner, F.J. Elling, K.U. Hinrichs, M. Kästner. SOIL BIOL BIOCHEM, 86:108-115(2015)

[11] C. Nicoletto, S. Santagata, G. Zanin, P. Sambo. SCI HORTIC-AMSTERDAM, 180:207-213(2014)

[12] W P. Yu, S J. Li, Q J. Ma, Y F. Wang, H S. Liu, et al. Commonly used dictionary of traditional Chinese medicine words. JINAN:(1998). (in Chinese with English abstract)

[13] J. Daintith. The Facts on File Dictionary of Chemistry. XIAN:(2018) (in Chinese with English abstract)

[14] J. Li, L. Xu, D.H. Wang. Effect of different chelating agent on heavy metal in soil, Journal of Liaoning University, 3:283-285(2008) (in Chinese with English abstract)

[15] W. Shao. Taiyuan University of Technology, (2015) (in Chinese with English abstract)

[16] Nanjing environmental science research institute of the state environmental protection administration. Environmental quality standard for soils. (in Chinese with English abstract)
[17] National agricultural technology extension service center. Organic fertilizer. (in Chinese with English abstract)

[18] Institute of biogas science, ministry of agriculture. Anaerobic digested fertilizer. (in Chinese with English abstract)

[19] South China agricultural university. Control limits against harmful substances in composts in composts for agricultural use. (in Chinese with English abstract)

[20] Chengdu soil and fertilizer test center. The rules of determining inferior fertilizer. (in Chinese with English abstract)

[21] Ministry of agriculture environmental protection research monitoring institute. Technology code for land application rates of livestock and poultry manure. (in Chinese with English abstract)

[22] Department of soil, fertilizer, resources and environment, Sichuan agriculture department. Guideline for safety application of zinc fertilizer. (in Chinese with English abstract)

[23] J. Guo. D.Ningxia University, (2013). (in Chinese with English abstract)

[24] L. Yi, Z.Q. Zhang, F. Shen, H. Liu. Journal of Northwest Agriculture, (01):156-160(2012). ( in Chinese with English abstract)

[25] F. S. Li, M. Han, D. Q. Xiong, G. L. Li, F. Liu, B. Q. Zhao, et al. Journal of Agro - Environ Sci, (06):704-706(2003). (in Chinese with English abstract)

[26] M. Chen, F. Bai, Y.S. Cui. Environmental Chemistry, 02:175-181(2012.) (in Chinese with English abstract)

[27] X. Liu. Northwest A \& F University, (2012). (in Chinese with English abstract)

[28] C. Xu, B.C. Xia, Y.Lin. Journal of Agro - Environ Sci, 0):1585-1589(2009). (in Chinese with English abstract)

[29] A. Ping, H. Nan. Agricultural Technology and Equipment, 06:24-25(2011) (in Chinese with English abstract)

[30] E. J. Kim, E. Jeon, K. Baek.Chemosphere ,152:274283(2016)

[31] H.M. Tan, Q.W. Tang. ENVIRON SCI TECHNOL, (01):35-36(1997) (in Chinese with English abstract)

[32] H.Y.Yu. Kunming University of Science and Technology, (2005) (in Chinese with English abstract)

[33] J.H. Xie. (D)Huazhong Agricultural University, (2010) (in Chinese with English abstract)

[34] R. Duan (D)Lanzhou University,2008. (in Chinese with English abstract)

[35] L. Zhao. (D)Shenyang Agricultural University, 2011. (in Chinese with English abstract)

[36] C.Y. Zhu. (D)Academy of Agricultural Sciences, (2009)(in Chinese with English abstract) 
[37] W.Q. Luo, Z. C. Jiang, Y. Deng, H.Y.Wu.

Chinese Journal of Geology, (03):221-227(2008) (in

Chinese with English abstract)

[38] X. L. Wang. (D)China Agricultural University, (2005) (in Chinese with English abstract) 